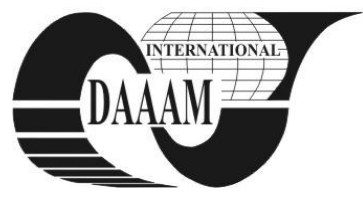

Annals of DAAAM for 2011 \& Proceedings of the 22nd International DAAAM Symposium, Volume 22, No. 1, ISSN 1726-9679 ISBN 978-3-901509-83-4, Editor B. Katalinic, Published by DAAAM International, Vienna, Austria, EU, 2011 Make Harmony between Technology and Nature, and Your Mind will Fly Free as a Bird Annals \& Proceedings of DAAAM International 2011

\title{
CERTAIN APPLICATIONS OF FRONTAL GEAR COUPLINGS
}

\author{
POP, P[etru] A[drian]; GORDAN, I[oan] M[ircea] \& GORDAN, C[ornelia] E[milia]
}

\begin{abstract}
The paper is presented the solutions of rational using of frontal rigid gear couplings with spherical gear in circle arc type Gleason with small dimensions. These gears are formed from two rings, one with concave gear and other with convex gear. The main characteristics of frontal gears are great twist moments of capacity transmission, precision angular position, fast central connection and assuring of optimal conditions for manufacturing of mass production and low cost. The application of frontal gears assured a higher accuracy of angular location of \pm 2 " and a great carrying capacity for couplings by using of compound rest of lathe with ultra precision location.
\end{abstract}

Key words: cycloid, frontal gear, meshing, spherical gear

\section{INTRODUCTION}

A frontal gear coupling is composed by two semicouplings, endowed with a gear disposed in a ratio of flat circular surface. The gears of these two semi-couplings are conjugate in meshing, so the teeth of one semi-coupling filled the blanks between teeth of second semi-coupling with the clearance between extreme surfaces of teeth. The mesh is rigid and without gap, having of auto-centered effect.

After the gear shaped, the frontal couplings can be classified in: frontal coupling with spur gear, named Hirth coupling, frontal coupling with helical gear, frontal coupling with curve gear (cycloid), named Oerlikon or Klingerber coupling, and frontal coupling with curved gear in circle arc and crowned (spherical), named Gleason gear. The gear couplings promoted by Gleason. were substituted gradual, the couplings type Hirth and type Klingerberg and Oerlikon, because of them high angular position of \pm 2 ', maxim capacity of moment's transmission and advanced proceeding of manufacturing of mass production on gear machine from Gleason Co.

\section{ELEMENTS OF FRONTAL GEAR COUPLING}

The frontal gear couplings with spherical gear have been executed of Stimin Co from Oradea by used the penetration method on gear machine G120 Gleason [Gleason Works], on grinding with grinding wheel type pot (Fig.1).

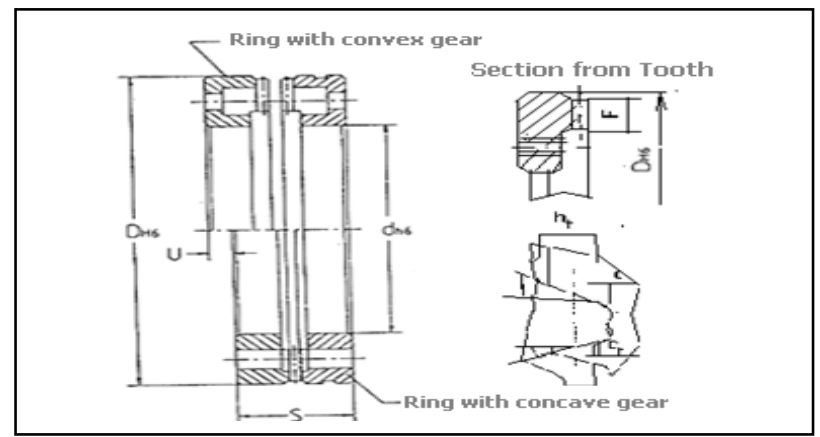

Fig. 1. Main section between frontal curved couplings
Where: $D_{H 6}=$ is external diameter of coupling, $d_{h 6}=$ inner diameter of coupling, $z=$ teeth number of coupling, $F=$ width of tooth, $h_{t}=$ height of tooth, $p=$ circular pitch of tooth; $2 \alpha=$ angle of axial shaped of grinding wheel type pot, $c=$ clearance of root tooth in meshing position of two semi-couplings, $U=$ minim distance between rings required in meshing, assured a new mesh in other position that the initial, and $S=$ width of Gleason coupling in meshing. The main relations [Ungur, et al. 2008; Vesselenyi, 1996] between gear's elements are:

○ Modulus-m:

$$
m=\frac{D_{H 6}}{Z}
$$

- Height of tooth- $\mathrm{h}_{\mathrm{t}}$ :

$$
h_{t}=0.88 \cdot m
$$

- Clearance of root tooth-c:

$$
c=0.10 \cdot m
$$

○ Head of tooth-a:

$$
a=\frac{h_{t}-c}{2}
$$

○ Pitch of tooth-b:

$$
b=h_{t}-a
$$

- Fillet radius of tooth $-\mathrm{c}_{\mathrm{f}}$ :

$$
c_{f}=0.09 \cdot m
$$

- Width of tooth-F:

$$
F=\frac{D_{H 6}-d_{h 6}}{2}
$$

The frontal crowned gear coupling realized at Stimin Co on gear's machine G120-Gleason is depicted in Fig.2. These couplings are standardized by the norms NT4051 and NT4052 [MICM-CIMUMFS].

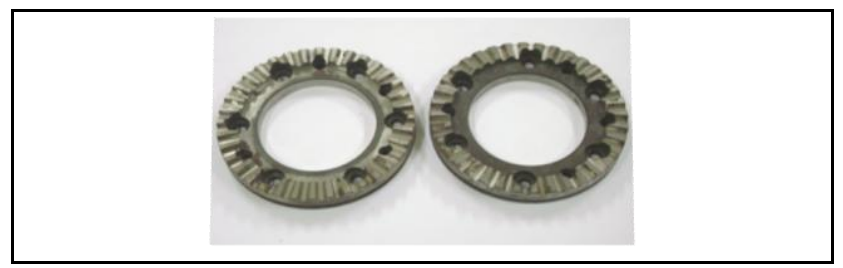

Fig. 2. The frontal crowned gear coupling with small diameter 


\section{APPLICATIONS OF FRONTAL GEARS COUPLINGS}

One application of crowned gear couplings is at head of toolholder ultra-precision for normal lathes. The most clamped devices of tools for lathe are heads of toolholder on a compound rest with positioning plate in four positions [Rieti et al, 1984]. This head toolholder (Fig.4) is composed from: 1compound rest, 2- bearing bracket, 3- screw M12x32, 4- nut, 5stub pin, 6- flat washer, 7- bearing, 8- coil spring, 9- semicoupling-I, 10- semi-coupling-II, 11- toolholder, 12-nut, 13screw, 14- feather key, 15- stud, 16- plate, 17- nut, 18- ball handle, 19- feather key, 20- stud, 21- ring, 22- nut, 23- bush, 24- screw, and 25- plate.

The main advantage of new construction vs. classical heat toolholder is get by its ultra-precision positioning of semicouplings in vertical position with rotated the toolholder in different angles, in dependence of teeth numbers of semicouplings used. That's was possible by get in the positioning chain of toolholder a pair of frontal crowned gear couplings of small size $(\varnothing 100 \mathrm{~mm})$, due to a ultra-precision head toolholder.

Other application of frontal crowned gear coupling is dividing ultra-flat table with direct differential dividing. The problem, which was resolved this application, is used a simple mathematical algorithm that allows a simple differential dividing, by used as support material more pairs of frontal crowned gear couplings in circle arc type curved with teeth numbers in conformity with technical norms.

For realizing of ultra-flat direct differential dividing device from two semi-couplings [Ungur et al, 2008] it's optimal the using of certain coaxial constructive solutions, in which the external diameter of one coupling has included by inner diameter of greater coupling. The required condition to realize a correct mounting is getting by:

$$
n \cdot p-m \cdot q=1
$$

Where: $(n)$ and $(m)$-are two real values of gear's couplings; $(p)$ and $(q)$-are two prime numbers between them. By notation $\mathrm{p}=$ $\mathrm{r} \cdot \mathrm{d}$ and $\mathrm{n}=1, \mathrm{~m}=\mathrm{k}$ the relation (8) became:

$$
r \cdot l \cdot d-k \cdot q=1
$$

The angular pitch of device- $P_{u}$ is getting by the relation:

$$
P_{u}=\frac{360^{0}}{k \cdot l \cdot d}
$$

By minimizing of the relation (10) with the calculus program [Ungur, et al. 2008; Vesselenyi, 1996] was obtained for $m=240$ teeth and $n=288$ teeth, with $k=5,1=6$ and $d=$ 48 , the value of angular pitch- $P_{u}$ is:

$$
P_{u}=\frac{360^{\circ}}{1440}=0.25^{0}=15^{\prime}
$$

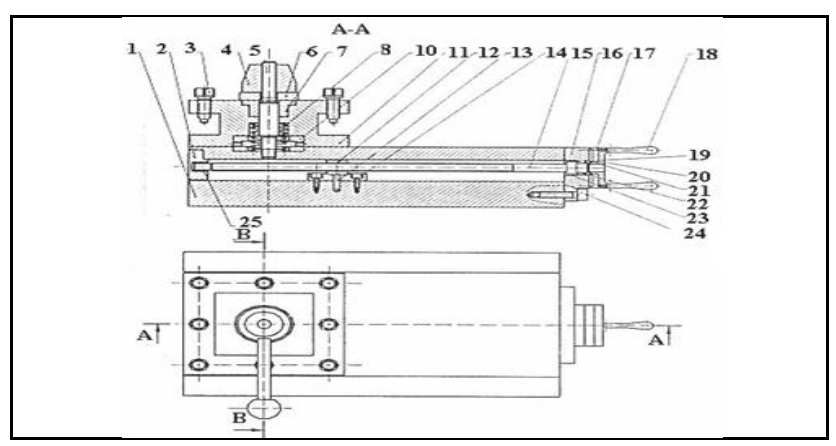

Fig. 3. The ultra-precision toolholder for lathes

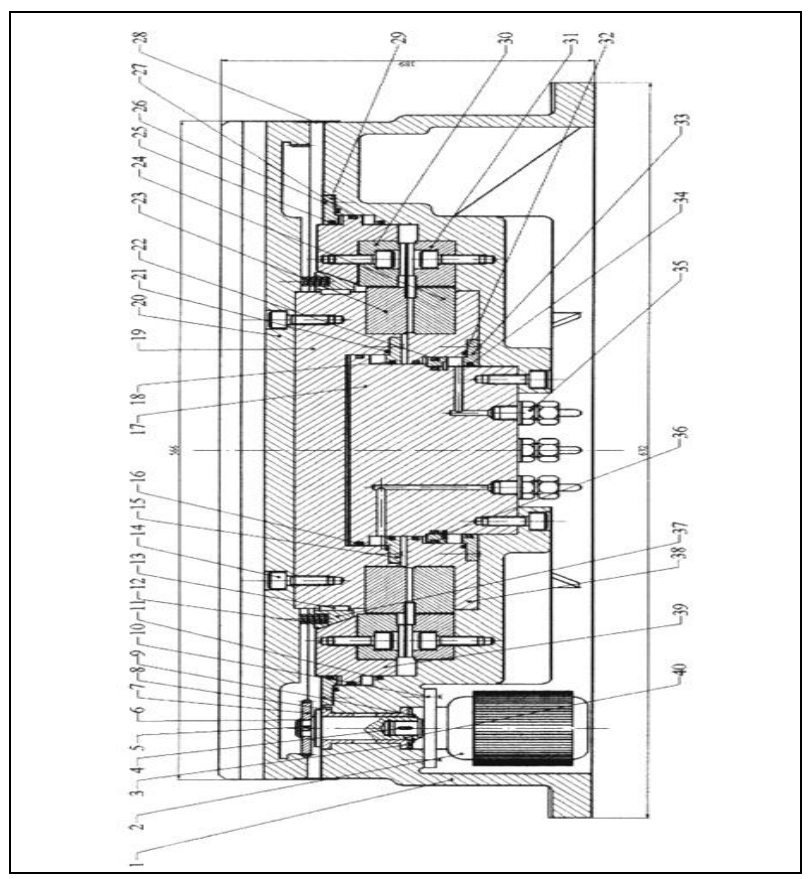

Fig. 4. The rotative table with simple differential dividing

In Fig. 4 is depicted the constructive solution of rotative table with device of simple differential dividing with frontal gear couplings. Where: 1-is the body, 2-electrical motor, 3,15,33-flange, 4,5,13-feather key, 6-spindle, 7-gear, 8-bush, 9lock washer, 10- flange of electrical motor, 11,16,18,25,26,27, 32-ring, 12-spring, 14-screw, 17-piston, 19-support, 20-rotated plate, 21-ring in O-shaped, 22-ring of ending, 23,24-frontal semi-couplings, 28-cover protection, 29-flange, 30-upper frontal semi-coupling, 31-under frontal semi-coupling, 34-tight ring, 35-junction, 37-located part, 38,39-pistons, 40-spindle.

The pistons would be acting with a pressure of $0.6 \mathrm{MPa}$ by a source of air compressed.

\section{CONCLUSION}

The frontal curved couplings by Gleason can be used in subassemblies of machine tools, cellular manufacturing systems, orientation devices and in other fields of machine construction, which performed the indexing for small number positions and at higher precision. These new solutions assure a complete interchangeable of gear couplings at low price.

\section{REFERENCES}

Reti, A., Sabau, I., Ungur, P., Gherman, I. (1985), "Head of simple toolholder for normal turning", Patent No.3440/1984, MIET-DT Romania

Ungur, P., Pop, P.A., Gordan, M., Gordan, C. (2008), "Rational using of small frontal rigid gear coupling type Gleason at simple direct and differential dividing and geometrical development of smaller size", Proceedings of DETC2008, ASME IDETC\&CIE Conference 3-6 Aug 2008, New York, ISBN 0-7918-3831-5, pp.1-8, ASME International Ed

Vesselenyi, T., Ungur, P., et al. (1996), "Software program used to obtain the file with the best parameters of grinding machines for curvic couplings", Annals of Oradea University, Mechanical Fascicle, pp.77, Oradea

*** "Operating Instructions for the Gleason 888(120), Curvic Coupling Grinder", Gleason Works

*** "Handbook Machine for Control of Gleason19 Coupling", Gleason Works

*** "Standardize Norm NT4051, NT4052, Frontal coupling with crowned gear", MICM-CIMUMFS-ICPMUA, Bucharest 